\title{
Um novo modelo de pesquisa de clima organizacional
}

\author{
Carlos Alberto Ferreira Bispo
}

EESC - USP

\section{Resumo}

O objetivo deste artigo é apresentar um novo modelo de pesquisa de clima organizacional aplicável a uma empresa de qualquer natureza, seja pública ou privada. Este modelo foi elaborado após terem sido realizadas pesquisas tanto na literatura pertinente como em empresas que já realizaram esta atividade e com profissionais da área de Recursos Humanos, Assistência Social e Assistência Médico-Hospitalar que já tiveram experiência com o levantamento e a análise do clima organizacional em empresas. Este modelo foi aplicado em duas empresas públicas de grande porte, obtendo bons resultados.

\section{Palavras-chave}

Gestão do clima organizacional, pesquisa de clima organizacional, gestão dos recursos humanos.

\section{A new model of organizational climate research}

\begin{abstract}
The aim of this work is to introduce a new model of Organizational Climate Research that may be applied in any type of enterprise, be it public or private. This model was worked on after a long bibliographical research as well as at companies that have already done this kind of work and also with professionals from area Human Resources, Social Works and Medical-Hospital Assistance, who had already had some experience in this area. This model was applied in two big public companies, obtaining good results.
\end{abstract}

\section{Key words}

Organizational climate management, organizational climate research, human resources management. 


\section{INTRODUĈ̣̃O}

Estão sendo desenvolvidas diversas ferramentas gerenciais para melhorar o nível de relacionamento entre as empresas e seus clientes. Porém, não estão sendo desenvolvidas, com a mesma intensidade, ferramentas gerenciais para melhorar o nível de relacionamento entre as empresas e os seus funcionários. Este artigo apresenta um novo modelo de uma das ferramentas que visam melhorar o nível de relacionamento entre as empresas e os seus funcionários, a pesquisa de clima organizacional.

Coda (1993) afirma que o clima organizacional é o indicador do grau de satisfação dos membros de uma empresa, em relação a diferentes aspectos da cultura ou realidade aparente da organização, tais como: política de RH, modelo de gestão, missão da empresa, processo de comunicação, valorização profissional e identificação com a empresa.

Para Payne e Mansfield (1973), o clima organizacional é considerado como o elo conceitual de ligação entre o nível individual e o nível organizacional, no sentido de expressar a compatibilidade ou congruência das expectativas, valores e interesses individuais com as necessidades, valores e diretrizes formais.

Segundo Chiavenato (2003), clima organizacional envolve uma visão mais ampla e flexível da influência ambiental sobre a motivação. É a qualidade ou propriedade do ambiente organizacional que é percebida ou experimentada pelos membros da organização e influencia no seu comportamento. Refere-se ao ambiente interno existente entre as pessoas que convivem no meio organizacional e está relacionado com o grau de motivação de seus participantes.

A pesquisa de clima organizacional é uma ferramenta objetiva e segura, isenta de comprometimento com a situação atual, em busca de problemas reais na gestão dos Recursos Humanos. A análise, o diagnóstico e as sugestões, proporcionados pela pesquisa, são valiosos instrumentos para o sucesso de programas voltados para a melhoria da qualidade, aumento da produtividade e adoção de políticas internas.

Os clientes, a empresa e os funcionários são beneficiados com um clima organizacional favorável. A recíproca também é verdadeira, ou seja, todos perdem com um clima organizacional desfavorável, conforme mostra a Figura 1.

Figura 1: Resultados proporcionados pelos recursos humanos com os diversos níveis de clima organizacional

\begin{tabular}{|c|c|c|}
\hline desfavorável & $\begin{array}{l}\text { CLIMA ORGANIZACIONAL } \\
\text { mais ou menos }\end{array}$ & favorável \\
\hline$\Rightarrow$ frustração, & $\Rightarrow$ indiferença, & $\Rightarrow$ satisfação, \\
\hline$\Rightarrow$ desmotivação, & $\Rightarrow$ apatia, & $\Rightarrow$ motivação, \\
\hline $\begin{array}{l}\Rightarrow \text { falta de integração empresa/ } \\
\text { funcionários, }\end{array}$ & $\begin{array}{l}\Rightarrow \text { baixa integração empresa/ } \\
\text { funcionários, }\end{array}$ & $\begin{array}{l}\Rightarrow \text { alta integração empresa/ } \\
\text { funcionários, }\end{array}$ \\
\hline $\begin{array}{l}\Rightarrow \text { falta de credibilidade mútua } \\
\text { empresa/funcionários, }\end{array}$ & $\begin{array}{c}\Rightarrow \text { baixa credibilidade mútua } \\
\text { empresa/funcionários, }\end{array}$ & $\begin{array}{c}\Rightarrow \text { alta credibilidade mútua } \\
\text { empresa/ funcionários, }\end{array}$ \\
\hline$\Rightarrow$ falta de retenção de talentos, & $\Rightarrow$ baixa retenção de talentos, & $\Rightarrow$ alta retenção de talentos, \\
\hline$\Rightarrow$ improdutividade, & $\Rightarrow$ baixa produtividade, & $\Rightarrow$ alta produtividade, \\
\hline$\Rightarrow$ pouca adaptação às mudanças, & $\Rightarrow$ média adaptação às mudanças, & $\Rightarrow$ maior adaptação às mudanças, \\
\hline$\Rightarrow$ alta rotatividade, & $\Rightarrow$ média rotatividade, & $\Rightarrow$ baixa rotatividade, \\
\hline$\Rightarrow$ alta abstenção, & $\Rightarrow$ média abstenção, & $\Rightarrow$ baixa abstenção, \\
\hline$\Rightarrow$ pouca dedicação, & $\Rightarrow$ média dedicação, & $\Rightarrow$ alta dedicação, \\
\hline $\begin{array}{l}\Rightarrow \text { baixo comprometimento com a } \\
\text { qualidade, }\end{array}$ & $\begin{array}{l}\Rightarrow \text { médio comprometimento com a } \\
\text { qualidade, }\end{array}$ & $\begin{array}{l}\Rightarrow \text { alto comprometimento com a } \\
\text { qualidade, }\end{array}$ \\
\hline$\Rightarrow$ clientes insatisfeitos, & $\Rightarrow$ clientes indiferentes, & $\Rightarrow$ clientes satisfeitos, \\
\hline $\begin{array}{l}\Rightarrow \text { pouco aproveitamento nos } \\
\text { treinamentos, }\end{array}$ & $\begin{array}{l}\Rightarrow \text { médio aproveitamento nos } \\
\text { treinamentos, }\end{array}$ & $\begin{array}{l}\Rightarrow \text { maior aproveitamento nos } \\
\text { treinamentos, }\end{array}$ \\
\hline $\begin{array}{l}\Rightarrow \text { falta de envolvimento com os } \\
\text { negócios, }\end{array}$ & $\begin{array}{l}\Rightarrow \text { baixo envolvimento com os } \\
\text { negócios, }\end{array}$ & $\begin{array}{l}\Rightarrow \text { alto envolvimento com os } \\
\text { negócios, }\end{array}$ \\
\hline $\begin{array}{l}\Rightarrow \text { crescimento das doenças } \\
\text { psicossomáticas, }\end{array}$ & $\Rightarrow$ algumas doenças psicossomáticas, & $\Rightarrow$ raras doenças psicossomáticas, \\
\hline$\Rightarrow$ insucesso nos negócios. & $\Rightarrow$ estagnação nos negócios. & $\Rightarrow$ sucesso nos negócios. \\
\hline
\end{tabular}




\section{MODELOS DE PESQUISA DE CLIMA ORGANIZACIONAL}

Segundo Rizzatti (2002), os estudos iniciais sobre clima organizacional surgiram nos Estados Unidos, no início dos anos 1960, com os trabalhos de Forehand e Gilmer sobre comportamento organizacional, dentro de um grande movimento da Administração chamado de Comportamentalismo. Este movimento buscou formas de combinar a humanização do trabalho com as melhorias na produção, buscando, principalmente na Psicologia, as ferramentas necessárias para alcançar esse objetivo. Os trabalhos de Forehand e Gilmer levantaram alguns conceitos e indicadores iniciais do clima organizacional a partir de estudos sobre comportamento individual realizados na Psicologia.

Posteriormente, Litwin e Stringer (1968) aproveitaram esses estudos e realizaram experiências em três diferentes organizações americanas. Os resultados demonstraram que cada uma das organizações apresentou três situações bem distintas em termos de satisfação e desempenho no trabalho. Esses resultados ajudaram a difundir os estudos sobre clima organizacional nas empresas, auxiliando outros estudos do movimento Comportamentalista.

No Brasil, a pesquisa de clima organizacional foi difundida e aplicada com Souza (1977, 1978, 1980, 1982, 1983), que realizou diversos trabalhos em empresas privadas e órgãos públicos utilizando adaptações do modelo de Litwin \& Stringer.

\section{_ por meio da pesquisa de clima organizacional que é possível se medir o nível de relacionamento entre os} funcionários e a empresa.

Baseado nos recentes trabalhos acadêmicos de Luz (2001), Rizzatti (2002) e Pereira (2003), apresentam-se os três principais modelos desenvolvidos especificamente para a pesquisa de clima organizacional para serem aplicados em empresas genericamente. Existem outros modelos desenvolvidos para empresas ou órgãos específicos, assim como modelos mais específicos da Psicologia, que serão apresentados após os três modelos principais. Logo após a apresentação dos modelos faz-se uma comparação entre os mesmos.

\section{Modelo de Litwin e Stringer}

O modelo de Litwin e Stringer (1968) utiliza um questionário baseado em nove fatores/indicadores:

- Estrutura - sentimento dos trabalhadores sobre as restri- ções em seu trabalho: muitas regras, regulamentos, procedimentos e outras limitações enfrentadas no desenvolver do trabalho;

- Responsabilidade - sentimento de autonomia para tomada de decisões relacionadas ao trabalho e a não dependência quando desempenha suas funções;

- Desafio - sentimento de risco na tomada de decisões e no desempenho das suas funções;

- Recompensa - sentimento de ser recompensado por um trabalho bem feito; ênfase em incentivos positivos e não em punições; sentimento sobre a justiça da política de promoção e remuneração;

- Relacionamento - sentimento de boa camaradagem geral e de ajuda mútua que prevalece na organização;

- Cooperação - percepção de espírito de ajuda e mútuo apoio vindo de cima (gestores) e de baixo (subordinados);

- Conflito - sentimento de que a administração não teme opiniões discrepantes e a forma mediadora utilizada para solução dos problemas;

- Identidade - sentimento de pertencer à organização, como elemento importante e valioso dentro do grupo de trabalho, em geral, a sensação de compartilhar objetivos pessoais com os objetivos organizacionais;

- Padrões - é o grau em que a organização enfatiza normas e processos.

\section{Modelo de Kolb}

O modelo de Kolb (KOLB et al., 1986) utiliza uma escala de sete fatores/indicadores. Além da responsabilidade, padrões e recompensas, já vistos no modelo anterior, há ainda os seguintes:

- Conformismo - sentimento de que existem muitas limitações externamente impostas na organização; o grau em que os membros sentem que há inúmeras regras, procedimentos, políticas e práticas às quais devem-se amoldar ao invés de serem capazes de fazer seu trabalho como gostariam de fazê-lo;

- Clareza Organizacional - sentimento de que as coisas são bem organizadas e os objetivos claramente definidos, ao invés de serem desordenados, confusos ou caóticos;

- Calor e Apoio - sentimento de que a amizade é uma forma valorizada na organização, onde os membros confiam uns nos outros e oferecem apoio mútuo. O sentimento de que boas relações prevalecem no ambiente de trabalho;

- Liderança-disposição dos membros da organização para aceitar a liderança e a direção de outros qualificados; quando surgem necessidades de liderança, os membros sentem-se livres para assumi-la e são recompensados por uma liderança bem-sucedida; a organização não é dominada por uma ou duas pessoas ou depende delas. 


\section{Modelo de Sbragia}

Sbragia (1983), num estudo empírico sobre o clima organizacional em instituição de pesquisa de natureza governamental, utiliza um modelo contendo vinte fatores/indicadores. Além de conformidade, estrutura, recompensas, cooperação, padrões, conflitos e identidade, há os seguintes fatores/indicadores:

- Estado de Tensão: descreve o quanto as ações das pessoas são dominadas por lógica e racionalidade antes do que por emoções;

- Enfase na Participação: descreve o quanto as pessoas são consultadas e envolvidas nas decisões; o quanto suas idéias e sugestões são aceitas;

- Proximidade da Supervisão: descreve o quanto a administração deixa de praticar um controle cerrado sobre as pessoas; o quanto as pessoas têm liberdade para fixar seus métodos de trabalho; o quanto as pessoas têm possibilidade de exercitar a iniciativa;

- Consideração Humana: descreve o quanto as pessoas são tratadas como seres humanos; o quanto recebem de atenção em termos humanos;

- Autonomia Presente: descreve o quanto as pessoas se sentem como seus próprios patrões; o quanto não precisam ter suas decisões verificadas;

- Prestígio Obtido: descreve a percepção das pessoas sobre sua imagem no ambiente externo pelo fato de pertencerem à organização;

- Tolerância Existente: descreve o grau com que os erros das pessoas são tratados de forma suportável e construtiva antes do que punitiva;

- Clareza Percebida: descreve o grau de conhecimento das pessoas relativamente aos assuntos que lhes dizem respeito; o quanto a organização informa às pessoas sobre as formas e condições de progresso;

- Justiça Predominante: descreve o grau que predomina nos critérios de decisão; as habilidades e desempenhos antes dos aspectos políticos, pessoais ou credenciais;

- Condições de Progresso: descreve a ênfase com que a organização provê a seus membros oportunidades de crescimento e avanço profissional; o quanto a organização atende suas aspirações e expectativas de progresso;

- Apoio Logístico Proporcionado: descreve o quanto a organização provê às pessoas as condições e os instrumentos de trabalho necessários para um bom desempenho; o quanto a organização facilita seus trabalhos principais;

- Reconhecimento Proporcionado: descreve o quanto a organização valoriza um desempenho ou uma atuação acima do padrão por parte de seus membros; o quanto os esforços individuais diferenciados são reconhecidos;

- Forma de Controle: descreve o quanto a organização usa custos, produtividade e outros dados de controle para efeito de auto-orientação e solução de problemas antes do policiamento e do castigo.

\section{Outros modelos}

Além dos três modelos apresentados acima, os modelos abaixo também constituem importantes estudos sobre clima organizacional, porém, com ênfase mais específica em alguma categoria de organização ou em algum assunto mais específico do próprio estudo de clima organizacional.

- Modelo de Coda - o professor Roberto Coda (CODA, 1997) desenvolveu seu modelo ao realizar estudos sobre motivação e liderança organizacional em cinco diferentes organizações brasileiras de grande porte do setor público e privado.

- Modelo de Kozlowski - criado por Steve Kozlowski e Mary Doherty (KOZLOWSKI; DOHERTY, 1989) a partir de estudos da Psicologia Aplicada, mais especificamente para avaliar a relação existente entre o clima organizacional e a liderança.

- Modelo de Levering - desenvolvido por Robert Levering (LEVERING, 1984 e 1997) foi criado originalmente para avaliar a correlação entre o desempenho econômico/financeiro das empresas e o nível de satisfação dos empregados com as mesmas.

- Modelo de Rizzatti - criado pela dissertação de mestrado de Gerson Rizzatti (RIZZATTI, 1995) especificamente para analisar o clima organizacional da Universidade Federal de Santa Catarina, sendo aperfeiçoado em sua tese de doutorado em 2002 (RIZZATTI, 2002), quando fez um estudo mais amplo envolvendo as universidades federais da Região Sul do Brasil.

\section{Avaliação dos modelos apresentados.}

O modelo de Litwin e Stringer foi o primeiro a ser testado em empresas de grande porte, permitiu uma comparação entre os resultados apresentados pelas empresas pesquisadas, demonstrando distintos climas organizacionais em empresas que tinham diferentes políticas para seus Recursos Humanos. Os resultados comprovaram a importância dos estudos sobre o clima organizacional nas empresas e reforçaram algumas teses do movimento Comportamentalista.

O modelo de Kolb surgiu duas décadas depois, também nos Estados Unidos, após estudos de sua equipe sobre o modelo desenvolvido por Litwin e Stringer, tentando aperfeiçoá-lo a partir dos progressos dos estudos da Psicologia Aplicada às organizações, conforme a Tabela 1.

O modelo do professor Roberto Sbragia, da Universidade de São Paulo, baseou-se ainda no modelo de Litwin \& Stringer, e foi elaborado a partir de um amplo estudo realizado em 13 instituições públicas de pesquisa no Brasil, realizado no início da década de 1980. É bem mais abrangente que os dois anteriores, conforme a Tabela 1. Esse estudo demonstrou 
várias deficiências institucionais com relação à política e estratégia de seus Recursos Humanos, não só nas empresas pesquisadas, mas com reflexos em outras empresas do setor público e em empresas do setor privado no Brasil.

A Tabela 1 mostra os fatores/indicadores utilizados em cada um dos três principais modelos apresentados e no modelo proposto por este artigo. Assim, é possível averiguar melhor as características de cada modelo.

O estudo realizado pelo professor Roberto Coda, da Universidade de São Paulo, para criar seu modelo foi bem mais amplo que os anteriores, analisando também a motivação, a cultura, o bem-estar e a liderança dos funcionários. Ele buscava novas estratégias para a gestão dos Recursos $\mathrm{Hu}$ manos. Com esse estudo bem mais amplo, ele deixou de dar um maior aprofundamento nos detalhes do levantamento do clima organizacional, empregando menos fatores/indicadores do clima organizacional que o modelo de Sbragia.

O modelo de Kozlowski foi desenvolvido mais especificamente para investigar um dos fatores/indicadores do clima organizacional, a liderança, comparando-a com os demais fatores/indicadores. Portanto, é um modelo mais voltado para o levantamento dos efeitos dos estilos de liderança na organização do que para o levantamento do clima organizacional.

Com os resultados obtidos pelo modelo de Levering, demonstrando a estreita relação entre o desempenho e o clima organizacional, o modelo foi adotado por uma grande empresa de consultoria dos EUA que também atua no Brasil

Tabela 1: Comparação das características dos três principais modelos de pesquisa de clima organizacional apresentados e do modelo proposto neste artigo

\section{FATORES/INDICADORES}

MODELO DE
LITWIN \&
STRINGER
DE KOLB
MODELO DE SBRAGIA

\section{Fatores internos}

Estrutura / regras

Responsabilidade / autonomia

Motivação (recompensa, promoção, remuneração, justiça]

Relacionamento / cooperação

Conflito

Identidade / orgulho

Clareza organizacional

Liderança / suporte

Participação / iniciativa / integração

Consideração / prestígio / tolerância

Oportunidade de crescimento / incentivos profissionais

Comunicação

Cultura organizacional

Estabilidade no emprego

Transporte casa/trabalho/casa

Nível sociocultural

\begin{tabular}{|c|c|c|}
\hline- & $X$ & $X$ \\
\hline$X$ & $X$ & - \\
\hline$X$ & $X$ & - \\
\hline- & $X$ & $X$ \\
\hline- & $X$ & - \\
\hline$X$ & $X$ & $X$ \\
\hline- & - & $X$ \\
\hline- & $X$ & $X$ \\
\hline- & $X$ & $X$ \\
\hline- & $X$ & - \\
\hline- & - & $X$ \\
\hline- & - & $X$ \\
\hline- & - & $X$ \\
\hline- & - & \\
\hline
\end{tabular}

\section{Fatores externos}

Convivência familiar

Férias / lazer

Saúde física e mental

Situação financeira familiar

Política / Economia local, nacional e internacional

Segurança pública

Vida social

Futebol 
e em outros países. Esse modelo tem sido usado para avaliar as cem melhores empresas para se trabalhar nestes países. Portanto, o modelo tem um enfoque mais específico, mostrando a qualidade de vida dos funcionários das empresas pesquisadas e sua relação com a imagem e o desempenho organizacional.

O modelo de Rizzatti, após os estudos concluídos em 2002, permitiu avaliar o clima organizacional nas universidades federais do sul do Brasil e forneceu dados importantes para a reavaliação e reestruturação de diversos aspectos organizacionais como: políticas e estratégias de recursos humanos, política de assistência e benefícios, estrutura organizacional, tecnologias educacionais, estilos de liderança, capacitação profissional, planejamento institucional, processo decisório, comunicação, conflitos de interesse, avaliação institucional, qualidade do ensino, autonomia universitária, etc. É, portanto, um modelo completo e muito adequado para o levantamento do clima organizacional em universidades federais, mas não pode ser aplicado genericamente em qualquer tipo de empresa, uma vez que já foi devidamente adaptado a uma determinada categoria de organização.

O modelo proposto, além de vários dos fatores/indicadores apresentados nos outros modelos, considera também outros fatores que influenciam as decisões, as atitudes e o comportamento dos funcionários. Esses novos fatores surgiram devido à evolução da Sociedade através da globalização, das inovações tecnológicas, da grande difusão das informações e do aumento da concorrência entre as empresas, o que fez com que essas exigissem mais de seus funcionários e esses, em contrapartida, mais cultos, mais informados e mais organizados, também passaram a exigir mais das empresas. Atualmente, esses funcionários também são influenciados por diversos fatores externos à empresa.

\section{O MODELO PROPOSTO}

Esse modelo é fruto de estudos na literatura pertinente e de sua aplicação em duas instituições públicas de grande porte, ambas com milhares de funcionários.

O modelo proposto não é fechado e nem será "patenteado" por este autor. Apresenta-se um modelo que está mais próximo da realidade atual das empresas. Por certo, ao ser divulgado, ocorrerão diversas críticas, comentários e sugestões. Alguém poderá querer aperfeiçoá-lo e lançar uma versão dois deste modelo, como aconteceu com outros modelos de ferramentas gerenciais. O importante é que a questão da geração ou aperfeiçoamento de ferramentas gerenciais que melhorem o relacionamento empresa/funcionários chegue próxima ao nível do desenvolvimento em que se encontram as ferramentas gerenciais para o aperfeiçoamento do relacionamento empresa/clientes.

O modelo proposto leva em consideração a evolução do cenário político-econômico, sociocultural e ecológico nacional e internacional. Para atender a essa necessidade, os macrofatores foram divididos em internos e externos.

\section{Análise, o diagnóstico e as sugestões, pela pesquisa, são valiosos o sucesso de programas voltados para melhoria da qualidade, aumento da adoção de políticas internas.}

Os fatores internos de influência são os que se originam dentro da própria empresa, sendo que essa pode atuar diretamente sobre esses fatores para tentar melhorá-los e produzir melhores resultados para a empresa, os clientes e os funcionários. São os fatores semelhantes aos que foram abordados nos modelos apresentados anteriormente.

Os fatores externos de influência são os que têm origem fora do âmbito da empresa, mas que exercem influência direta no comportamento, ações e decisões dos funcionários dentro da empresa, por isso não podem ser desprezados. Se a empresa não puder atuar diretamente sobre eles, pode tentar atuar sobre seus efeitos nos funcionários. Esses fatores sempre existiram, porém, sua influência atualmente é muito maior que no passado.

No modelo proposto, buscam-se os níveis de influência dos fatores internos e externos listados a seguir em ordem alfabética. Esses fatores foram delineados baseados na literatura e na nova realidade percebida pelos diversos profissionais de Recursos Humanos nas duas empresas em que a pesquisa de clima organizacional foi aplicada.

\section{Fatores internos de influência:}

- Ambiente de trabalho - estabelece o grau de relacionamento entre os colegas de trabalho, necessário para realização das atividades individuais ou coletivas;

- Assistência aos funcionários - estabelece o nível da assistência médica, dentária, hospitalar e social aos funcionários;

- Burocracia - avalia se este item está compatível com as atividades realizadas pelos funcionários;

- Cultura organizacional - avalia o nível de interferência que as tradições, práticas e costumes, adotados informal- 
mente na empresa, exercem sobre os funcionários e suas atividades;

- Estrutura organizacional - mede o nível de relacionamento e de capacitação dos elementos que compõem esta estrutura e sua interferência nas atividades realizadas pelos funcionários;

- Nível sociocultural - procura estabelecer se os níveis intelectual, cultural e social dos funcionários estão de acordo com as necessidades inerentes às suas atividades;

- Incentivos profissionais - visam estabelecer o nível de reconhecimento profissional dos funcionários;

- Remuneração - avalia se este item está de acordo com as atividades prestadas à empresa;

- Segurança profissional - avalia o risco de demissão sem motivo percebido pelos funcionários;

- Transporte casa/trabalho - trabalho/casa - mede o nível de dificuldade encontrado para a locomoção entre a casa dos funcionários e a empresa e vice-versa; e

- Vida profissional - estabelece o grau de identificação profissional dos funcionários com a empresa, tentando medir o nível de seu orgulho em relação à empresa e de seu sucesso profissional. boa remuneração não é suficiente para que ele tenha uma boa situação financeira. Este item tenta avaliar como está a situação financeira dos funcionários;

- Time de futebol - item que já foi comprovado cientificamente que tem influência sobre a produtividade dos funcionários, este item tenta medir, portanto, o nível de interferência que os times de futebol exercem sobre a motivação e a produtividade dos funcionários; e

- Vida social - avalia o nível de satisfação dos funcionários com este item.

\section{A APLICAC̣̃̃O DA PESQUISA DE CLIMA ORGANIZACIONAL}

Existe uma vasta literatura abordando como aplicar uma pesquisa de campo por meio de formulários de pesquisa e de como analisar e interpretar os dados levantados. Este artigo não tem a intenção de discutir esse assunto, porém, com base na experiência adquirida por este autor na aplicação desta pesquisa em duas instituições públicas de grande porte, é possível apresentar algumas recomendações específicas para a aplicação desse tipo de pesquisa.

Recomenda-se que esse tipo de pesquisa seja realizado por alguma empresa totalmente independente da organização onde será aplicada a pesquisa. Desta forma, podem-se obter resultados mais próximos da realidade da empresa, mais precisos e livres de influências ou pressões de quaisquer tipos. A aplicação da pesquisa por pessoas da própria empresa poderia proporcionar resultados indu-

\section{Fatores externos de influência}

- Convivência familiar - procura avaliar o nível da convivência familiar dos funcionários, item necessário para uma boa produtividade nas atividades realizadas na empresa;

- Férias e lazer - avaliam o grau de satisfação dos funcionários com estes itens, os quais também são necessários para garantir uma boa produtividade;

- Investimentos e despesas familiares - procuram avaliar o nível do bem-estar proporcionado às famílias dos funcionários;

- Política e Economia - tentam avaliar o nível de interferência proporcionado por estes itens na motivação dos funcionários;

- Saúde - tenta avaliar a opinião dos próprios funcionários sobre suas respectivas saúdes física e mental, um dos itens de extrema importância e de difícil observação;

- Segurança Pública - avalia o nível de influência deste item na vida diária dos funcionários;

- Situação financeira - o fato de um funcionário ter uma zidos ou os funcionários poderiam não ficar totalmente à vontade para preencher as fichas de pesquisa e apresentar críticas e sugestões na folha avulsa. Dessa forma, os resultados obtidos com a pesquisa não retratariam com fidelidade o clima organizacional da empresa. Porém, várias empresas têm elaborado e aplicado sua própria pesquisa e obtido bons resultados.

\section{O levantamento dos dados}

O modelo proposto foi aplicado nas duas instituições por meio de fichas de avaliação. Na prática, em cada empresa onde foi realizada a pesquisa foi feita uma adaptação dessas fichas, de acordo com as características e as necessidades de cada uma delas. As fichas de avaliação utilizadas no artigo apresentam as questões mais comuns a todo tipo de empresa.

Para a aplicação da pesquisa utilizam-se duas fichas e uma folha avulsa, além de uma folha de introdução (Anexo 1) ao preenchimento da fichas de pesquisa. A primeira ficha (Anexo 2) permite fazer o levantamento do nível atual em 
que se encontram os fatores internos de influência. A segunda ficha (Anexo 3 ) faz o mesmo com os fatores externos de influência. A folha avulsa (Anexo 4) permite que cada funcionário relate suas observações ou comentários sobre sua opção em algum ou em vários dos itens que compõem as duas fichas de pesquisa, permite que relate ainda suas queixas, críticas, sugestões ou elogios referentes à empresa, às suas atividades, ao seu relacionamento com seus pares, superiores ou subordinados, ou a qualquer outro item que desejar, o importante é que o funcionário manifeste abertamente e sinceramente suas opiniões e seus sentimentos.

Antes de iniciar a coleta de dados, é necessário fazer um amplo trabalho de conscientização junto aos funcionários para demonstrar a finalidade e a importância da pesquisa de clima organizacional. Nesta conscientização, é necessário frisar a importância da máxima sinceridade nas respostas para que seja possível obter os dados mais fiéis possíveis mostrando claramente como está o nível de relacionamento entre a empresa e os seus funcionários.

Deve ser salientado que todos os funcionários receberão o material que faz parte da pesquisa (Anexos 1, 2, 3 e 4), porém a participação na pesquisa é totalmente voluntária, ou seja, quem não quiser participar não será obrigado a fazê-lo. Saliente-se também que quanto mais funcionários participarem da pesquisa, mais real será o cenário traçado e pode ser feito um melhor trabalho para se corrigir eventuais distorções que estajam ocorrendo no relacionamento entre a empresa e seus funcionários.

Os funcionários devem ser avisados de que não precisam colocar qualquer tipo de identificação nas fichas de pesquisa e na folha avulsa. A preocupação central da pesquisa é levantar o clima organizacional e não o clima individual de cada funcionário. Nas três fichas a serem preenchidas não há sequer um espaço reservado para a identificação do funcionário. Porém, quem quiser se identificar poderá fazê-lo sem problemas. A experiência prática mostrou que vários funcionários preferiram se identificar na folha avulsa, onde eles manifestam suas críticas, sugestões e reivindicações.

Deve ser salientado, também, que mesmo que a análise final dos resultados demonstre que o clima organizacional está desfavorável e existe uma enorme e perigosa insatisfação com a empresa por parte da maioria dos funcionários, não haverá, como conseqüência da pesquisa, qualquer tipo de represália ou qualquer outro tipo de retorno que possa vir a prejudicar qualquer funcionário. O objetivo da aplicação da pesquisa é melhorar o relacionamento entre a empresa e os funcionários e não piorar a situação existente, seja ela qual for.

Os funcionários devem ser conscientizados para que caso algum deles queira se manifestar de forma mais direta, isso pode ser feito por meio da folha avulsa (Anexo 4). Nessa folha podem ser relatados observações, comentários, rei- vindicações, queixas, críticas, sugestões ou elogios a algum dos itens que constam nas fichas de pesquisa, à empresa, ao departamento ou à seção onde o funcionário trabalha, ao seu chefe imediato, à hierarquia a que o funcionário está subordinado ou a algum de seus membros, ao sistema de trabalho, às instalações, às condições de trabalho, às normas de trabalho, ao tratamento recebido de seus superiores, aos colegas de trabalho, ao ambiente de trabalho, etc.

Em outros modelos de pesquisa de clima organizacional, há quatro alternativas de resposta para cada item avaliado. No modelo proposto, para facilitar as respostas dos funcionários, propõe-se que sejam adotadas apenas três alternativas, que depois de compiladas permitem aos analistas montarem um cenário do clima organizacional da empresa conforme mostrado na Figura 1. Mas as empresas que julgarem necessário utilizar mais alternativas ou a tradicional escala de Likert (1932), com cinco opções, ou ainda a escala de Osgood (1969), com sete opções, poderão fazê-lo sem problemas.

Deve ser esclarecido aos funcionários sobre a subjetividade das respostas, pois é provável que alguns funcionários fiquem em dúvida sobre qual alternativa assinalar em alguns itens, devido ao fato de que o contexto envolvido naqueles itens é muito complexo e de difícil análise. Nestes casos, os funcionários são incentivados a preencher também a Folha Avulsa anexa às Fichas de Pesquisa.

\section{Análise dos resultados \\ e mapeamento dos problemas}

Encerrada a fase de coleta de dados, inicia-se a tabulação dos dados obtidos e a análise dos resultados. Mais uma vez, existe uma vasta literatura abordando este assunto e não se pretende discuti-lo neste artigo. Porém, baseado na experiência adquirida pela aplicação nas duas empresas de grande porte, algumas recomendações podem ser feitas.

Os dados levantados na Folha Avulsa (Anexo 4) também devem ser tabulados, analisados e confrontados com os dados das Fichas de Pesquisa 1 e 2 (Anexos 2 e 3). A experiência obtida com a aplicação da pesquisa mostra que os dados levantados por meio da Folha Avulsa reforçam e esclarecem os resultados obtidos nas Fichas de Pesquisa 1 e 2, principalmente quando se trata de resultados ruins que indicam problemas. A experiência tem mostrado que os funcionários insatisfeitos estão mais dispostos a se manifestar de todas as formas possíveis que os funcionários que se encontram satisfeitos com suas atividades.

Os dados levantados nas Fichas de Pesquisa 1 e 2, reforçados pelos dados levantados pela Folha Avulsa, permitem realizar um mapeamento dos principais problemas inerentes ao relacionamento entre a empresa e os funcionários, dos problemas reais - aqueles que já estão ocorrendo na empresa - e dos problemas latentes - aqueles que já possuem indícios de sua existência mas que ainda não estão se manifestando plenamente. 


\section{Elaboração e implementação dos planos de ação para se solucionar os problemas encontrados}

Após o mapeamento dos problemas, é necessário elaborar-se um plano de ação para solucioná-los no curto prazo e tomar-se medidas organizacionais de longo prazo para uma solução definitiva, como as apresentadas na conclusão. Recomenda-se que cada empresa e/ou cada setor encontre a melhor solução para os problemas levantados. A solução de cada problema vai depender de sua gravidade; dos recursos necessários para a solução, incluindo os financeiros, materiais, humanos e o fator tempo; do relacionamento do problema encontrado com outros problemas detectados e a sua solução conjunta; do esforço conjunto e da confiança mútua entre a empresa e seus funcionários para a solução destes problemas; e da capacidade dos administradores em encontrar boas soluções para os mesmos.

\section{CONCLUSÕES}

A aplicação do modelo proposto neste artigo nas duas instituições públicas permitiu avaliar com bastante realismo o clima organizacional naquelas organizações, levantando seus problemas, críticas e sugestões, o que permitiu sanar diversos pequenos problemas e encontrar caminhos viáveis para a solução de outros problemas de maior porte, ambos desconhecidos da alta administração e que comprometiam um melhor clima organizacional. Os dados obtidos também permitiram reavaliar e/ou reestruturar diversos aspectos organizacionais como: políticas e estratégias de recursos humanos, estrutura e complexidade organizacional, tecnologias utilizadas, estilos de liderança, capacitação profissional, planejamento organizacional, processos decisórios, comunicação, conflitos de interesse, cultura organizacional, assistência aos funcionários, investimentos, relacionamento com a comunidade, imagem organizacional, etc.

O levantamento dos fatores externos de influência permitiu averiguar melhor como anda a qualidade de vida dos funcionários, assim como elaborar melhor as políticas e as estratégias dos recursos humanos, levando em consideração os resultados apresentados por estes fatores. Os setores de assistência aos funcionários foram os mais envolvidos neste aspecto. Uma maior preocupação com os aspectos sociais dos funcionários e um maior relacionamento com a comunidade local também resultaram desse levantamento.

Por meio do novo modelo da ferramenta gerencial apresentado neste artigo, é possível para qualquer empresa detectar melhor como está o seu clima organizacional e a qualidade de vida de seus funcionários, assim como levantar os problemas inerentes ao relacionamento com seus funcionários. Este artigo propõe-se a mostrar uma forma de levantar os problemas, porém, a solução dos mesmos vai depender dos recursos disponíveis, do estilo gerencial, da política e da estratégia para os Recursos Humanos de cada empresa. Por isso, cada empresa terá que solucionar seus problemas da melhor forma possível dentro de suas limitações.

Espera-se que este artigo possa vir a ajudar muitas empresas que estejam enfrentando dificuldades no relacionamento com seus empregados, trazendo diversos tipos de prejuízos à empresa. Possa também auxiliar as empresas que desejarem saber como anda o seu clima organizacional ou aquelas que queiram melhorá-lo continuamente, sempre com a intenção de poder desfrutar os benefícios que um bom clima organizacional pode proporcionar às empresas, aos seus funcionários, aos seus clientes e à sua comunidade.

\section{Artigo recebido em 07/04/2004 Aprovado para publicação em 23/05/2005}

\section{- Referências Bibliográficas}

CHIAVENATO, I. Introdução à teoria geral da administração: uma visão abrangente da moderna administração das organizações. Rio de Janeiro: Elsevier, 7. ed, 2003

CODA, R. Estudo sobre clima organizacional traz contribuição para aperfeiçoamento de pesquisa na área de RH. In: Boletim Administração em Pauta, suplemento da Revista de Administração, São Paulo. IA-USP, n. 75, dez., 1993.

CODA, R. Pesquisa de clima organizacional e gestão estratégica de recursos humanos. In: BERGAMINI, C. W.; CODA; R. (organizadores). Psicodinâmica da vida organizacional: motivação e liderança. São Paulo: Atlas, 1997.

KOLB, D. A. et al. Psicologia Organizacional: uma abordagem vivencial. São Paulo, Atlas, 1986.

KOZLOWSKI, S. W. J.; DOHERTY, M. L. Integration of climate and leadership: examination of a neglected issue. Journal of Applied Psychology, v. 74, n. 4, p. 546553, 1989.
LEVERING, R. The 100 best companies to Work for in America. New York: AddisonWesley, 1984

LEVERING, R. Um excelente lugar para se trabalhar: o que torna alguns empregadores tão bons e outros tão ruins. Rio de Janeiro: Qualitymark Editora, 1997.

LIKERT, R. A technique for the measurement of attitudes. Archives of Psychology, n. 140 , p. $1-50,1932$.

LITWIN, G. H., STRINGER, R. A. Motivation and organizational climate. Cambridge: Harvard University Press, 1968.

LUZ, J. P. Metodologia para análise de clima organizacional: um estudo de caso para o Banco do Estado de Santa Catarina. Florianópolis, 2001. Dissertação (Mestrado) - Programa de Pós Graduação em Engenharia de Produção - UFSC.

OSGOOD, C. E. The measurement of meaning. In: SNIDER, J. G.; OSGOOD, C. E. Semantic differential technique. Chicago: Aldine Publishing, 1969, p. 3-41. 
PAYNE, R. L.; MANSFIELD, R. Relationship of perceptions of organizational climate to organizational structure, context e hierarchical position. Administrative Science Quarterly, n. 18, p. 515-526, 1973.

PEREIRA, L. A. (2003) Poder e clima organizacional: um estudo de caso em uma empresa petroquímica. Florianópolis, 2003. Dissertação (Mestrado). Departamento de Engenharia de Produção e Sistemas, Universidade Federal de Santa Catarina.
RIZZATTI, G. Análise de fatores significativos do clima organizacional da UFSC: contribuição para implantação do programa de qualidade. Florianópolis. Dissertação (Mestrado). Departamento de Engenharia de Produção e Sistemas, Universidade Federal de Santa Catarina, 1995.

RIZZATTI, G. Categorias de análise de clima organizacional em universidades federais brasileiras. Florianópolis, 2002. Tese (Doutorado). Departamento de Engenharia de Produção e Sistemas, Universidade Federal de Santa Catarina.
SBRAGIA, R. Um estudo empírico sobre clima organizacional em instituições de pesquisa. Revista de Administração, v. 18, n. 2, p. 30-39, 1983.

SOUZA, E. L. P. Diagnóstico de clima organizacional. Revista de Administração Pública, v. 11, n. 2, p. 141-58, abr./jun., 1977.

SOUZA E. L. P. Clima e cultura organizacionais: como se manifestam e como se manejam. São Paulo: Edgard Blucher, 1978.
SOUZA, E. L. P. Percepção de clima conforme escalão hierárquico. Revista de Administração de Empresas, v. 20, n. 4, p. 51-56, out./nov., 1980.

SOUZA, E. L. P. Clima e motivação em uma empresa estatal. Revista de Administração de Empresas, v. 22, n. 1, p. 18-38, 1982.

SOUZA, E. L. P. Clima e estrutura de trabalho. Revista de Administração, v. 18 n. 3, p. 68-71, jul./set., 1983.

\section{- Sobre o autor}

\section{Carlos Alberto Ferreira Bispo}

Universidade de São Paulo

Doutorando do Departamento de Engenharia de Produção da Escola de Engenharia de São Carlos

End.: Rua Santo Antonio, 142 - Pirassununga - SP - CEP 13632-000

E-mail: cafbispo@sc.usp.br ou cafbispo@uol.com.br

\section{ANEXO 1}

\section{Introdução ao preenchimento das fichas de pesquisa e da folha avulsa}

Para que uma empresa se torne moderna, com produtos ou serviços competitivos e com qualidade comprovada, com a imagem consolidada tanto pelos clientes como pelos seus funcionários, como o mercado exige atualmente, é necessário que a empresa mantenha um bom relacionamento não somente com os clientes, mas também com seus funcionários. Uma forma de avaliar esse relacionamento é aplicando uma pesquisa de clima organizacional.

Todos os funcionários receberão o material que faz parte dessa pesquisa, porém a participação na pesquisa é voluntária, se você não quiser participar não será obrigado a fazê-lo, porém, quanto mais funcionários participarem, mais real será o cenário traçado e poderá ser feito um melhor trabalho para se corrigir eventuais distorções que estajam ocorrendo no relacionamento entre a empresa e os funcionários.

Repare em todas as folhas desse material e verifique que não existe qualquer espaço reservado para a sua identificação. Você não precisa colocar qualquer tipo de identificação, porém, se você quiser se identificar, não há problemas.

Você ou qualquer outro funcionário jamais poderá ser prejudicado por ter participado da pesquisa e ter fornecido informações valiosas para a avaliação do relacionamento entre a empresa e os funcionários, mesmo porque, como não é exigida qualquer identificação, não há a possibilidade e nem a intenção de se saber a avaliação individual de qualquer funcionário. Mesmo que a análise final dos resultados demonstre que existe uma enorme e perigosa insatisfação dos funcionários com a empresa, não haverá qualquer tipo de represália ou qualquer outro tipo de retorno que venha a prejudicar você ou qualquer outro funcionário.

Esse material que você e todos os demais funcionários estão recebendo e que compõe a pesquisa é composto por duas fichas de pesquisa e uma folha avulsa para as suas observações. Nas fichas de pesquisa são levantados quais são os fatores que influenciam o relacionamento entre os 
funcionários e a empresa. Esses fatores influenciam o nosso comportamento, as nossas decisões e as nossas atitudes de forma direta ou indireta, normalmente alterando para melhor ou para pior o nosso estado de ânimo, o nosso humor e a nossa motivação. Existem dois tipos de fatores de influência: os internos e os externos.

Os fatores internos de influência são os que se originam dentro da própria empresa, eles podem ser trabalhados na empresa para que produzam resultados positivos tanto para os funcionários quanto para a empresa. Eles são os itens que constam na primeira ficha de pesquisa. Após o levantamento da situação de cada item por meio da pesquisa, será possível se elaborar planos de ação para proporcionar melhorias nos itens que receberem uma avaliação ruim e reforçar os itens que receberem uma avaliação positiva.

Os fatores externos de influência são os que se originam fora da empresa, porém eles exercem influência nos funcionários dentro da empresa, por isso não podem ser desprezados. Esses fatores podem ser trabalhados pela empresa não na sua origem, mas nos efeitos que produzem nos funcionários. São os itens que constam na segunda ficha de pesquisa. Após o levantamento da situação de cada item por meio da pesquisa, será possível elaborar planos de ação para se tentar amenizar a ação negativa dos itens que receberem uma avaliação ruim.

Para cada item que consta nas duas fichas de pesquisa existem três alternativas de resposta. Você precisará marcar com um $\mathbf{X}$ uma única alternativa para cada item, aquela que mais se aproxime da sua análise individual de cada item. As três alternativas são:
> Alternativa 1 - $\mathbf{s i m}$ - marque esta alternativa se você concorda com a afirmação contida no item que está sendo avaliado;

Alternativa 2 - mais ou menos - marque esta alternativa se você concorda apenas parcialmente com a afirmação no item que está sendo avaliado;

$>$ Alternativa 3 - não - marque esta alternativa se você não concorda com a afirmação contida no item que está sendo avaliado.

Porém, se você ficar em dúvida na escolha da melhor alternativa de algum item, devido à necessidade de dar maiores explicações a respeito de sua opinião sobre aquele item, você poderá fazer uso da folha avulsa para fazer as suas observações esta folha se encontra logo após as duas fichas de pesquisa.

Você poderá preencher as fichas de pesquisa e a folha avulsa na empresa ou levar para preencher em casa. O mais importante é que você e os demais funcionários se manifestem de forma sincera e sem qualquer interferência ou influência de quem quer que seja (chefe, colegas de trabalho ou familiares), isto para que os dados fornecidos retratem da forma mais fiel possível a realidade do relacionamento entre a empresa e os funcionários e se possa traçar bons planos de ação para se corrigir as distorções.

É importante que todos os itens sejam preenchidos, porém, os itens que você não souber ou não quiser responder podem ser deixados em branco.

Auxilie-nos! Todos seremos beneficiados! Contamos com você!

Muito obrigado.

\section{ANEXO 2 \\ Ficha de pesquisa no 1 \\ Levantamento dos fatores internos de influência do relacionamento entre os funcionários e a empresa}

\section{Vida Profissional}

1. Sinto orgulho de trabalhar nesta empresa.
( ) não
( ) mais ou menos
( ) sim

2. Sinto orgulho da minha atividade nesta empresa.
( ) não
( ) mais ou menos
( ) sim 
3. Acho que a empresa me oferece um bom plano de carreira.
( ) não
( ) mais ou menos
( ) $\operatorname{sim}$

4. Costumo indicar esta empresa como alternativa de emprego para meus amigos e parentes.
( ) não
( ) mais ou menos
( ) $\operatorname{sim}$

5. Eu me preocupo com o futuro desta empresa.
( ) não
( ) mais ou menos
( ) $\operatorname{sim}$

6. Considero que estou obtendo sucesso na minha carreira e na minha vida profissional.
( ) não
[ ] mais ou menos
( ) $\operatorname{sim}$

7. Gostaria que meus filhos trabalhassem nesta empresa.
( ) não
( ) mais ou menos
( ) $\operatorname{sim}$

8. Dependo apenas dos meus próprios esforços para obter o sucesso profissional e de carreira na empresa.
( ) não
( ) mais ou menos
( ) $\operatorname{sim}$

9. Os cursos e treinamentos que fiz são suficientes para o exercício das minhas atividades.
( ) não
( ) mais ou menos
( ) $\operatorname{sim}$

\section{Estrutura Organizacional}

10. Eu confio plenamente no meu chefe imediato.
( ) não
( ) mais ou menos
[ ] $\operatorname{sim}$

11. O meu chefe imediato é um líder.
( ) não
( ) mais ou menos
( ) sim

12. O meu chefe imediato é a pessoa mais indicada para a função que ocupa.
( ) não
( ) mais ou menos
( ) sim

13. Estou satisfeito com a estrutura hierárquica (chefes e subordinados] a que estou vinculado.
( ) não
( ) mais ou menos
( ) sim

\section{Incentivos Profissionais}

14. Considero que o meu trabalho é reconhecido e valorizado pela empresa.
( ) não
( ) mais ou menos
( ) $\operatorname{sim}$

15. Considero que o meu trabalho é reconhecido e valorizado pela minha família.
( ) não
( ) mais ou menos
( ) sim

16. Considero que o meu trabalho é reconhecido e valorizado pelos meus amigos e parentes.
( ) não
( ) mais ou menos
( ) $\operatorname{sim}$

\section{Remuneração}

17. Acho justo o meu salário atual.
( ) não
( ) mais ou menos
( ) $\operatorname{sim}$

18. 0 meu patrimônio é condizente com os esforços que tenho feito pela empresa.
( ) não
( ) mais ou menos
( ) $\operatorname{sim}$ 


\section{Segurança Profissional}

19. Meu emprego é seguro na empresa, ou seja, não corro o risco de ser demitido sem motivo.

( ) não ( ) mais ou menos ( ) sim

\section{Nível Sociocultural}

20. O meu nível cultural e intelectual é suficiente para o exercício das minhas atividades na empresa.
( ) não
( ) mais ou menos
( ) $\operatorname{sim}$

21. O meu nível social é suficiente para o exercício das minhas atividades na empresa.
( ) não
( ) mais ou menos
( ) $\operatorname{sim}$

\section{Transporte dos Funcionários}

22. Tenho tido problemas com o transporte casa-empresa/empresa-casa.
( ) não
( ) mais ou menos
( ) sim

\section{Ambiente de Trabalho}

23. O ambiente de trabalho favorece a execução das minhas atividades na empresa.
( ) não
( ) mais ou menos
( ) $\operatorname{sim}$

24. O relacionamento com meus colegas de trabalho favorece a execução das minhas atividades na empresa.
( ) não
( ) mais ou menos
( ) $\operatorname{sim}$

\section{Burocracia}

25. A burocracia adotada na empresa favorece a execução das minhas atividades na empresa.
( ) não
( ) mais ou menos
( ) $\operatorname{sim}$

\section{Cultura Organizacional}

26. A Cultura Organizacional (tradições, práticas e costumes adotados na empresa que não estão previstos em qualquer regral adotada na empresa favorece a execução das minhas atividades na empresa.
( ) não
( ) mais ou menos
( ) $\operatorname{sim}$

\section{Assistência aos Funcionários}

27. A assistência de médico e dentista e a assistência social adotadas na empresa favorecem a execução das minhas atividades na empresa.
( ) não
( ) mais ou menos
( ) $\sin$ 


\section{ANEXO 3}

Ficha de pesquisa $n^{\circ} 2$

Levantamento dos fatores externos de influência do relacionamento entre os funcionários e a empresa

\section{Investimentos e Despesas Familiares}

1. Eu me preocupo com o futuro da minha família.
( ) não
( ) mais ou menos
( ) $\operatorname{sim}$

2. Eu me preocupo com o futuro dos meus filhos.
( ) não
( ) mais ou menos
( ) $\operatorname{sim}$

3. Estou satisfeito com a alimentação que estou podendo proporcionar à minha família.
( ) não
( ) mais ou menos
( ) $\operatorname{sim}$

4. Estou satisfeito com a educação que estou podendo proporcionar aos meus filhos.
( ) não
( ) mais ou menos
[ ] $\operatorname{sim}$

\section{Convivência Familiar}

5. Estou vivendo bem com a minha esposa/companheira ou o meu marido/companheiro.
( ) não
( ) mais ou menos
( ) $\operatorname{sim}$

6. Estou vivendo bem com os meus filhos.
( ) não
( ) mais ou menos
( ) $\operatorname{sim}$

\section{Situação Financeira}

7. Estou satisfeito com a minha residência.
( ) não
( ) mais ou menos
( ) $\operatorname{sim}$

8. Estou satisfeito com o meu carro.
( ) não
( ) mais ou menos
( ) $\sin$

9. Estou satisfeito com o vestuário que estou podendo proporcionar à minha família.
( ) não
( ) mais ou menos
[ ] $\operatorname{sim}$

10. Estou com a minha situação financeira em ordem.
( ) não
( ) mais ou menos
( ) $\operatorname{sim}$

11. Estou satisfeito com o meu patrimônio.
( ) não
( ) mais ou menos
( ) $\operatorname{sim}$

\section{Vida Social}

12. Estou satisfeito com o meu nível social.
( ) não
( ) mais ou menos
(] $\operatorname{sim}$

13. Estou satisfeito com o meu convívio social.
( ) não
( ) mais ou menos
( ) $\operatorname{sim}$

14. Estou satisfeito com o meu nível intelectual.
( ) não
( ) mais ou menos
( ) $\operatorname{sim}$ 
15. Estou satisfeito com o meu nível cultural.
( ) não
( ) mais ou menos
( ] $\operatorname{sim}$

16. Estou satisfeito com a minha religião.
( ) não
( ) mais ou menos
( ) $\operatorname{sim}$

\section{Saúde}

17. Estou satisfeito com as minhas práticas desportivas.
( ) não
( ) mais ou menos
[ ] sim

18. Estou satisfeito com o meu estado físico.
( ) não
( ) mais ou menos
[ ] $\operatorname{sim}$

19. Estou satisfeito com o meu estado mental.
( ) não
( ) mais ou menos
( ) $\operatorname{sim}$

\section{Convivência Familiar}

20. Estou satisfeito com a minha vida afetiva.
( ) não
( ) mais ou menos
( ) sim

21. Estou satisfeito com a minha vida sexual.
( ) não
( ) mais ou menos
( ) $\operatorname{sim}$

\section{Time de Futebol}

22. Estou satisfeito com o time de futebol para o qual eu torço.
( ) não
( ) mais ou menos
( ) $\operatorname{sim}$

\section{Férias e Lazer}

23. Estou satisfeito com as minhas últimas férias.
( ) não
( ) mais ou menos
[ ] sim

24. Estou planejando para que as minhas próximas férias sejam muito boas.
( ) não
( ) mais ou menos
[ ] $\operatorname{sim}$

\section{Segurança Pública}

25. Estou satisfeito com o atual estágio da segurança pública.
( ) não
( ) mais ou menos
( ) $\operatorname{sim}$

26. A corrupção altera o meu estado de ânimo.
( ) não
( ) mais ou menos
( ) $\operatorname{sim}$

27. A violência altera o meu estado de ânimo.
( ) não
( ) mais ou menos
( ) sim

28. A impunidade altera o meu estado de ânimo.
( ) não
( ) mais ou menos
( ) $\operatorname{sim}$ 


\section{Política e Economia}

29. Estou satisfeito com o atual estágio da política nacional.

( ) não ( ) mais ou menos ( ) sim

30. Estou satisfeito com o atual estágio da política estadual.

( ) não ( ) mais ou menos ( ) sim

31. Estou satisfeito com o atual estágio da política municipal.

( ) não ( ) mais ou menos ( ) sim

32. As crises políticas alteram o meu estado de ânimo.

( ) não ( ) mais ou menos ( ) sim

33. As crises econômicas alteram o meu estado de ânimo.
( ) não
( ) mais ou menos
( ) $\operatorname{sim}$

34. As crises internacionais alteram o meu estado de ânimo.
( ) não
( ) mais ou menos
( ) $\operatorname{sim}$

\section{ANEXO 4}

\section{Folha avulsa para as suas observações}

Nessa folha você pode relatar as suas observações, os seus comentários, as suas reivindicações, as suas queixas, as suas críticas, as suas sugestões ou os seus elogios a algum dos itens que constam nas duas fichas de pesquisa, referente à empresa, ao departamento ou à seção onde você trabalha, ao seu chefe imediato, à estrutura hierárquica, ao sistema de trabalho, às instalações, às condições de trabalho, às normas de trabalho, à forma de tratamento recebida de seus chefes, aos seus colegas de trabalho, ao seu ambiente de trabalho, etc. Sinta-se à vontade para relatar e revelar tudo o que desejar sem constrangimentos. Lembre-se que você não precisa se identificar, a menos que queira fazê-lo. As suas sinceras observações serão valiosas para a pesquisa. Podem ser utilizadas quantas linhas ou quantas folhas forem necessárias. 